\title{
Arctic Snow Microstructure Experiment for the development of snow emission modelling
}

\author{
William Maslanka ${ }^{1}$, Leena Leppänen ${ }^{2}$, Anna Kontu ${ }^{2}$, Mel Sandells $^{3}$, Juha Lemmetyinen ${ }^{2}$, Martin Schneebeli ${ }^{4}$, \\ Martin Proksch ${ }^{4}$, Margret Matzl ${ }^{4}$, Henna-Reetta Hannula ${ }^{2}$, and Robert Gurney ${ }^{1}$ \\ ${ }^{1}$ Department of Meteorology, University of Reading, Reading, UK \\ ${ }^{2}$ Finnish Meteorological Institute, Arctic Research Centre, Sodankylä, Finland \\ ${ }^{3}$ CORES Science and Engineering LTD, Burnopfield, UK \\ ${ }^{4}$ WSL Institute of Snow and Avalanche Research, SLF, Davos, Switzerland \\ Correspondence to: William Maslanka (w.maslanka@pgr.reading.ac.uk)
}

Received: 27 November 2015 - Published in Geosci. Instrum. Method. Data Syst. Discuss.: 18 December 2015

Revised: 24 March 2016 - Accepted: 30 March 2016 - Published: 14 April 2016

\begin{abstract}
The Arctic Snow Microstructure Experiment (ASMEx) took place in Sodankylä, Finland in the winters of 2013-2014 and 2014-2015. Radiometric, macro-, and microstructure measurements were made under different experimental conditions of homogenous snow slabs, extracted from the natural seasonal taiga snowpack. Traditional and modern measurement techniques were used for snow macroand microstructure observations. Radiometric measurements of the microwave emission of snow on reflector and absorber bases were made at frequencies 18.7, 21.0, 36.5, 89.0, and 150.0 GHz, for both horizontal and vertical polarizations. Two measurement configurations were used for radiometric measurements: a reflecting surface and an absorbing base beneath the snow slabs. Simulations of brightness temperatures using two microwave emission models, the Helsinki University of Technology (HUT) snow emission model and Microwave Emission Model of Layered Snowpacks (MEMLS), were compared to observed brightness temperatures. RMSE and bias were calculated; with the RMSE and bias values being smallest upon an absorbing base at vertical polarization. Simulations overestimated the brightness temperatures on absorbing base cases at horizontal polarization. With the other experimental conditions, the biases were small, with the exception of the HUT model $36.5 \mathrm{GHz}$ simulation, which produced an underestimation for the reflector base cases. This experiment provides a solid framework for future research on the extinction of microwave radiation inside snow.
\end{abstract}

\section{Introduction}

Snow is a vital component of the water cycle, and is critically important for meteorological and climatological studies due to its high albedo, high thermal emissivity, and thermal insulating properties (Cohen and Rind, 1991). In addition, over 1 billion people rely on snowmelt for their fresh water drinking supply (Barnett et al., 2005). To predict and monitor the evolution of potential snowmelt, continuous observations of key parameters such as snow water equivalent (SWE), height of snowpack (HS, as defined by Fierz et al., 2009), and snow extent (SE) are required throughout the year. While traditional snow pit and automatic weather station observations are important, remote sensing observations of snow with passive microwave radiometers are currently the only means in northern countries to provide vital global daily measurements of snow properties. As snow crystals act as scattering centres for upwelling microwave radiation, the size of the snow crystal, the radiation wavelength (and therefore its frequency), and the snow depth all play a role in dictating the amount of scattering present in a snowpack (Chang et al., 1987; Hallikainen et al., 1987).

Over the last 30 years, space-borne passive microwave observations have been used to estimate snow mass and SWE (Chang et al., 1987; Hollinger et al., 1990; Kelly et al., 2003; Takala et al., 2011). The basis of snow mass estimates (Chang et al., 1987) is based on comparison of the observed brightness temperature at a frequency where scattering by the snow crystals is dominant $(>25 \mathrm{GHz}, 37 \mathrm{GHz}$ 
is commonly used) with the observed brightness temperature at a frequency where scattering is not dominant $(<25 \mathrm{GHz}$, $19 \mathrm{GHz}$ is commonly used). Numerous empirical formulae were developed for estimating SWE from the passive microwave observations (Künzi et al., 1982; Chang et al., 1987; Hallikainen, 1989; Amlien, 2008); however, relying on rigid regression coefficients, these empirical approaches were often only valid for certain regional areas with poor interannual consistency (Derksen et al., 2003). Purely theoretical models for snow emission have also been developed (e.g. Tsang et al., 2000). However, these models tend to be very complex and due to the diversity of ancillary information required, their use in practical SWE retrieval from satellite observations is limited. Sitting between empirical and theoretical models are semi-empirical models; these combine radiative transfer theory with results from observations, adjusting key model components empirically. Two commonly used semi-empirical models are the Helsinki University of Technology (HUT) snow emission model (Pulliainen et al., 1999; Lemmetyinen et al., 2010) and the Microwave Emission Model of Layered Snowpacks (MEMLS, Wiesmann and Mätzler, 1999; Mätzler and Wiesmann, 1999).

Both the HUT snow emission model and MEMLS use snow parameters to describe the snowpack and snow microstructure. These parameters include physical temperature, density, and some form of microstructure parameter. This microstructure parameter (describing size, shape, orientation of snow grains) has a large effect on the observed brightness temperature (Foster et al., 1999; Armstrong et al., 1993) because the intensity of scattered microwave radiation is directly linked to snow microstructure (Chang et al., 1987). However, the amount of scattering, described by the scattering coefficient in both the HUT snow emission model and MEMLS, is empirically defined based on observations (Pulliainen et al., 1999; Wiesmann and Mätzler, 1999; Pan et al., 2015). However, MEMLS also includes an option to define the scattering coefficient purely on a physical basis (Mätzler and Wiesmann, 1999).

The Arctic Snow Microstructure Experiment (ASMEx) took place at the Arctic Research Centre of Finnish Meteorological Institute (FMI-ARC) in Sodankylä, Finland in the winter seasons of 2013-2014 and 2014-2015. During the ASMEx, macro-, microstructure, and radiometric measurements of homogeneous snow slabs were made. The snow slabs were extracted from the natural seasonal taiga snowpack. The radiometric measurements were made on two different bases: one assumed perfect absorber and one perfect reflector. Observations of snow macro- and microstructure were made after radiometric measurements. The observed parameters were fed into the HUT snow emission model and MEMLS to produce simulated brightness temperatures. Only homogeneous slabs of dry snow were considered for microwave emission simulation. This was to avoid using wet snow in the radiometric measurements, as the dielectric properties of dry and wet snow are very different. The real and imaginary parts of the dielectric constant of water are much greater than those of ice (Stiles and Ulaby, 1981), increasing the complexity of the behaviour of the dielectric properties of snow.

This paper uses both the HUT snow emission model and MEMLS to simulate the microwave emission of homogenous snow slabs extracted from the natural snowpack in FMI-ARC during ASMEx, and compares simulated and observed microwave emission from the snow slabs. The ultimate aim of ASMEx is to improve the understanding of the microwave extinction processes within the snowpack, and their relation to microstructural properties of natural snow cover. This will enable to improve the precision of future and existing snow emission models.

\section{Methods and models}

\subsection{Methods}

\subsubsection{Excavation of snow slabs}

The snow slabs were extracted from the natural snowpack in the intense observation area (IOA) of the FMI-ARC that is situated in the clearing of a sparse pine forest, in Sodankylä, Finland. A snow sample of size $80 \times 60 \mathrm{~cm}$ was mechanically removed from the snowpack. The thickness of these slabs varied typically between 14 and $19 \mathrm{~cm}$, with the exception of one slab, comprised of depth hoar, being approximately $5 \mathrm{~cm}$ thick. Snow slabs were taken from different depths within the snowpack, in order to capture a range of grain sizes and types. The snow slabs were taken at different periods during the two winters of ASMEx, to capture a wider range of grain sizes and types. Each of the snow slabs was extracted from a homogeneous layer, and its stratigraphy was manually assessed after the radiometric measurements.

The preparation and extraction of the snow slabs was a delicate process. Once a homogeneous layer of sufficient thickness was selected, the sample was prepared by pushing a metal plate (surrounded by a microwave transparent plastic sheet to avoid snow freezing to the metal plate, both at ambient temperature) into the snowpack and selecting the snow sample with a plastic frame as shown in Fig. 1. The plastic frame was also allowed to cool to the ambient temperature, in order to reduce the snow melt-freeze problem. Cuts were made to the surface snow, using metal plates and saws, parallel to the sides of the plastic frame. This allowed the frame to sink to the level of the embedded metal frame. All cuts were made outside to the plastic frame, in order to limit the disruption to the potential sample. Once the plastic frame was level with the metal plate, the entire sampling apparatus and snow sample were pulled out of the snowpack. Any snow above the slab sample and plastic frame was removed. The top of the snow sample was carefully smoothed with a metal plate as gently as possible without making artificial features 


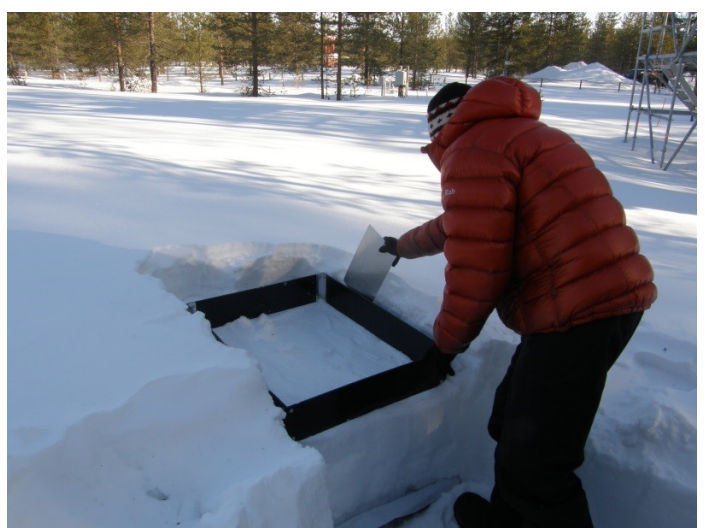

Figure 1. Snow sample was taken from snowpack with a plastic frame, a metal plate and a saw, and a metal bottom plate surrounded by a plastic sheet.

on the slab surface. Immediately after extraction, the slabs were placed in front of the radiometer for brightness temperature measurements. A total of 14 samples were extracted in that manner.

\subsubsection{Radiometric measurements}

The microwave radiometric measurements were made with two RPG-XCH-DP Dicke Switch radiometers, installed on top of the radiometric tower in the IOA. The experimental set up of radiometric measurements is described in Fig. 2. Five different frequencies $(18.7,21.0,36.5,89.0$, and $150.0 \mathrm{GHz})$ at both horizontal and vertical polarizations were used, although not all frequencies were working for all slabs. Tables 1 and 2 detail the radiometric data collected from the ASMEx slabs in 2014 and 2015, respectively. The radiometric measurements were made at an inclination angle of $50^{\circ}$. Equivalent sky brightness temperatures were also made to measure the intensity of the downwelling radiation.

Radiometric measurements followed a comparable procedure as in Wiesmann et al. (1998). The first measurement was made with the snow slab on top of the reflective metal base. The metal base acts as a perfect reflector by reflecting the downwelling emission of microwave radiation from the sky. Once the snow slab had been observed at all frequencies, sky measurements at an equivalent incidence angle were made. The metal plate was then carefully removed from the set up, so that the snow slab was upon the assumed perfect absorber. The radiometric measurements were then repeated. Emissivity tests of the absorbing material, using the experimental setup in Fig. 2 without the snow slab and metal plate, proved that the assumption of a near-perfect blackbody was valid for all slab experiments, with the exception of slabs B05 and B07. For these two slabs, the metal strips in the tape, used to hold the top-most piece of Styrofoam together, caused a reduction in brightness temperature at horizontal polarizations at different frequencies. A

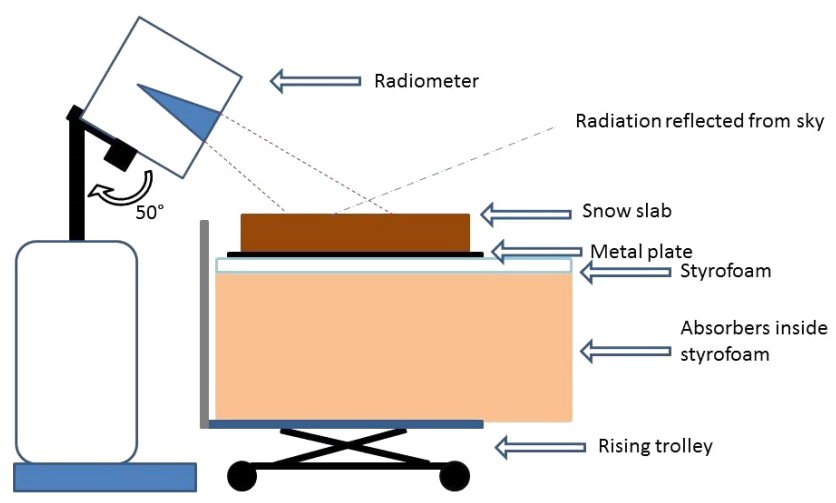

Figure 2. Setup for radiometer measurements with a $50^{\circ}$ inclination angle.

correction (none at $18.7 \mathrm{GHz},-1 \mathrm{~K}$ at $21.0 \mathrm{GHz},-2 \mathrm{~K}$ at $36.5 \mathrm{GHz},-8 \mathrm{~K}$ at $89.0 \mathrm{GHz}$, and $-15 \mathrm{~K}$ at $150.0 \mathrm{GHz}$ ) was applied to the absorbing base brightness temperature data for slabs B05 and B07.Throughout the radiometric measurements the physical temperatures of snow, air, and absorbing material were also measured for modelling purposes.

\subsubsection{Measurements of snow macro- and microstructure}

Once the radiometric measurements had been completed, the destructive sampling of the physical parameters of snow macro- and microstructure took place. Initially, the stratigraphy of the slab was observed using the SnowMicroPen (SMP; Schneebeli and Johnson, 1998 and Schneebeli et al., 1999). The SMP uses a sensitive piezoelectric force sensor on top of a penetrative rod, which is capable of detecting changes in penetrative resistance at a high resolution $(4 \mu \mathrm{m})$. A total of 12 SMP profiles were taken across each slab to assess the stratigraphy and homogeneity. The nominal locations of the SMP profiles, as well as all other macro- and microstructure measurements, are shown in Fig. 3. From the SMP profiles, it is possible to detect layers as well as produce profiles of density, correlation length, and specific surface area (SSA) of the snow (Proksch et al., 2015). For the purposes of this experiment, nine slabs (eight dry and one wet) could be considered homogeneous, with minimal horizontal and vertical features. The other five slabs exhibited significant vertically layered structures, and contained features such as ice crusts within the snow. These internal features would produce additional scattering and internal reflections that would be difficult to quantify in the models for simulation.

The SSA is defined as the ratio between the surface area of the ice and its mass (Legagneux et al., 2002). A new method for measuring the SSA is the IceCube instrument, which is a commercially available version of DUFISSS (Gallet et al., 2009). The IceCube instrument uses a $1310 \mathrm{~nm}$ infrared laser to measure the hemispherical reflectance from the sample. 
Table 1. Radiometric data measured from the 2014 ASMEx slabs. Brightness temperatures from reflective base $\left(T_{\mathrm{BM}}\right)$, sky after reflective base measurements $\left(T_{\mathrm{BM}, \mathrm{SKY}}\right)$, absorbing base $\left(T_{\mathrm{BA}}\right)$, and sky after absorbing base measurements $\left(T_{\mathrm{BA}, \mathrm{SKY}}\right)$ are presented. Horizontal (vertical) brightness temperatures are shown.

\begin{tabular}{|c|c|c|c|c|c|c|c|c|c|}
\hline \multirow[t]{2}{*}{ Sample } & \multirow{2}{*}{$\begin{array}{r}\text { Freq } \\
(\mathrm{GHz})\end{array}$} & \multicolumn{2}{|c|}{$T_{\mathrm{BM}}(\mathrm{K})$} & \multicolumn{2}{|c|}{$T_{\mathrm{BM}, \mathrm{SKY}}(\mathrm{K})$} & \multicolumn{2}{|c|}{$T_{\mathrm{BA}}(\mathrm{K})$} & \multicolumn{2}{|c|}{$T_{\mathrm{BA}, \mathrm{SKY}}(\mathrm{K})$} \\
\hline & & H pol & V pol & H pol & V pol & H pol & V pol & H pol & $\mathrm{V}$ pol \\
\hline A01 & 18.7 & 22.94 & 23.43 & 18.06 & 17.90 & 243.27 & 258.29 & 14.01 & 13.24 \\
\hline A01 & 21.0 & 30.42 & 30.87 & 24.11 & 24.01 & 238.51 & 257.81 & 18.59 & 18.74 \\
\hline A01 & 36.5 & 51.66 & 52.13 & 38.21 & 38.58 & 243.80 & 257.82 & 25.23 & 25.51 \\
\hline A02 & 21.0 & 46.41 & 54.53 & 15.22 & 15.83 & 152.52 & 217.99 & 14.39 & 14.85 \\
\hline A02 & 36.5 & 93.71 & 115.81 & 23.89 & 24.98 & 144.62 & 192.49 & 22.21 & 23.39 \\
\hline A03 & 18.7 & 37.28 & 35.96 & 19.57 & 19.83 & 255.18 & 272.08 & 19.57 & 19.83 \\
\hline A03 & 21.0 & 50.94 & 50.87 & 32.01 & 32.13 & 257.10 & 272.19 & 32.01 & 32.13 \\
\hline A04 & 18.7 & 77.45 & 79.14 & 19.30 & 19.16 & 221.22 & 254.11 & 19.30 & 19.16 \\
\hline A04 & 21.0 & 111.81 & 111.96 & 29.17 & 29.09 & 217.65 & 248.46 & 29.17 & 29.09 \\
\hline A05 & 18.7 & 47.95 & 48.96 & 19.43 & 17.84 & 225.19 & 262.16 & 19.79 & 18.51 \\
\hline A05 & 21.0 & 63.11 & 64.68 & 28.63 & 28.70 & 239.14 & 263.03 & 29.36 & 29.46 \\
\hline A05 & 89.0 & 180.79 & 201.66 & 54.13 & 53.37 & 193.85 & 202.99 & 65.79 & 65.02 \\
\hline A05 & 150.0 & 205.16 & 212.83 & 96.23 & 100.98 & 205.65 & 212.11 & 109.70 & 111.87 \\
\hline A06 & 18.7 & 28.54 & 31.80 & 7.40 & 9.11 & 228.19 & 256.50 & 8.29 & 9.87 \\
\hline A06 & 21.0 & 41.92 & 45.64 & 12.63 & 12.23 & 235.55 & 256.59 & 13.46 & 12.77 \\
\hline A06 & 89.0 & 177.19 & 192.06 & 29.48 & 27.36 & 185.05 & 198.34 & 29.58 & 27.76 \\
\hline A06 & 150.0 & 181.88 & 188.24 & 42.61 & 34.88 & 184.20 & 189.46 & 47.66 & 35.22 \\
\hline A07 & 18.7 & 27.34 & 27.94 & 9.78 & 10.20 & 229.06 & 258.48 & 10.58 & 11.00 \\
\hline A07 & 21.0 & 37.85 & 38.03 & 13.80 & 14.40 & 224.12 & 257.64 & 14.55 & 14.59 \\
\hline A07 & 89.0 & 165.43 & 183.30 & 30.17 & 30.54 & 168.96 & 186.30 & 30.17 & 30.54 \\
\hline A07 & 150.0 & 175.07 & 186.75 & 45.36 & 39.93 & 174.46 & 187.88 & 45.36 & 39.93 \\
\hline
\end{tabular}

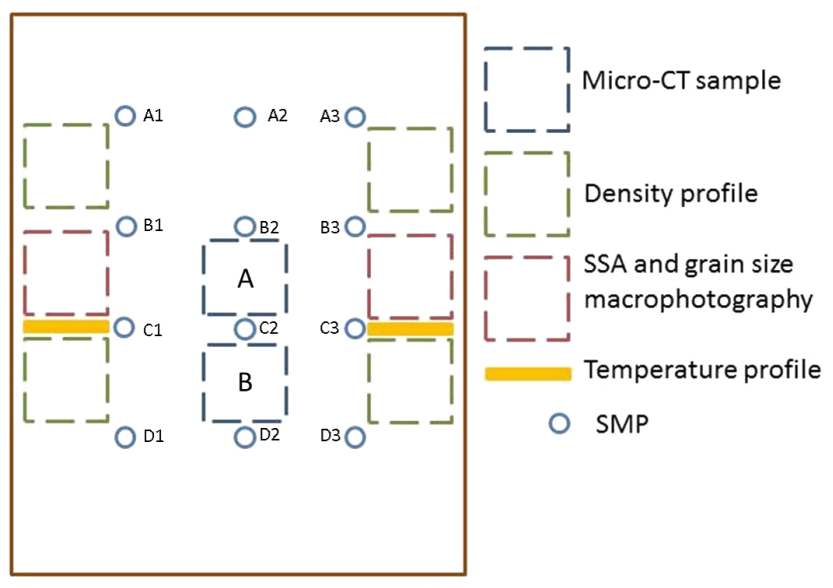

Figure 3. Approximate locations of the macro- and microstructure measurements in the snow slab. Individual SMP and micro-CT measurement locations are also depicted.

The SSA of the snow slab was measured at two different locations in a vertical profile with $3 \mathrm{~cm}$ intervals. The traditional grain size, $E$, is defined by Fierz et al. (2009) as largest extent of an average grain. In this study, post-processed visual estimation of traditional grain size was made from the macrophotographs to improve repeatability of the estimation. Snow grains from the SSA samples were collected and sep- arated upon a $1 \mathrm{~mm}$ reference grid for macrophotography, in order to have profiles of traditional grain size and SSA from the same location. Traditional grain size was estimated visually from macrophotographs with $0.25 \mathrm{~mm}$ resolution.

Snow samples were taken from the centre of the radiometer footprint to be scanned with microcomputed tomography (micro-CT) apparatus. The cast samples were analysed via three-dimensional $\mathrm{x}$-ray tomography in WSL Institute of Snow and Avalanche Research, SLF, Switzerland, to produce a three dimensional image of the snow (Heggli et al., 2009). From this image, it is possible to measure many important microstructural parameters, especially a vertically highly resolved profile of density and correlation length.

In addition to the different number of microstructural measurements of the snow slab, vertical profiles of physical temperature and density took place in other locations within the slab with a vertical resolution of $5 \mathrm{~cm}$. The density profiles were made using a density cutter with a volume of $500 \mathrm{~cm}^{3}$.

\subsection{Models}

\subsubsection{Helsinki University of Technology snow emission model}

The Helsinki University of Technology (HUT) snow emission model (Pulliainen et al., 1999; Lemmetyinen et al., 2010) is a semi-empirical model, which uses the radiative 
Table 2. Radiometric data measured from the 2015 ASMEx slabs (horizontal/vertical polarization). Brightness temperatures from reflective base $\left(T_{\mathrm{BM}}\right)$, sky after reflective base measurements $\left(T_{\mathrm{BM}, \mathrm{SKY}}\right)$, absorbing base $\left(T_{\mathrm{BA}}\right)$, and sky after absorbing base measurements $\left(T_{\mathrm{BA}, \mathrm{SKY}}\right)$ are presented.

\begin{tabular}{|c|c|c|c|c|c|c|c|c|c|}
\hline \multirow[t]{2}{*}{ Sample } & \multirow{2}{*}{$\begin{array}{r}\text { Freq } \\
(\mathrm{GHz})\end{array}$} & \multicolumn{2}{|c|}{$T_{\mathrm{BM}}(\mathrm{K})$} & \multicolumn{2}{|c|}{$T_{\mathrm{BM}, \mathrm{SKY}}(\mathrm{K})$} & \multicolumn{2}{|c|}{$T_{\mathrm{BA}}(\mathrm{K})$} & \multicolumn{2}{|c|}{$T_{\mathrm{BA}, \mathrm{SKY}}(\mathrm{K})$} \\
\hline & & $\mathrm{H}$ pol & V pol & $\mathrm{H}$ pol & V pol & $\mathrm{H}$ pol & V pol & $\mathrm{H}$ pol & $\mathrm{V}$ pol \\
\hline B01 & 18.7 & 18.73 & 18.33 & 10.87 & 9.82 & 246.71 & 257.23 & 11.04 & 9.74 \\
\hline B01 & 21.0 & 28.69 & 28.69 & 17.92 & 17.49 & 245.98 & 258.02 & 17.83 & 17.46 \\
\hline B01 & 36.5 & 42.71 & 44.08 & 21.99 & 22.48 & 241.77 & 254.49 & 21.58 & 21.81 \\
\hline B02 & 18.7 & 20.60 & 19.30 & 8.66 & 8.21 & 229.52 & 251.64 & 7.51 & 6.49 \\
\hline B02 & 21.0 & 30.56 & 28.61 & 13.69 & 13.72 & 231.56 & 252.80 & 11.77 & 11.65 \\
\hline B02 & 36.5 & 54.75 & 54.55 & 24.00 & 24.27 & 228.46 & 247.58 & 19.49 & 19.86 \\
\hline B03 & 18.7 & 24.64 & 23.74 & 13.33 & 11.84 & 234.63 & 264.68 & 13.30 & 11.48 \\
\hline B03 & 21.0 & 37.70 & 36.85 & 24.79 & 23.76 & 243.67 & 265.30 & 24.15 & 23.13 \\
\hline B03 & 36.5 & 57.32 & 56.63 & 27.16 & 26.32 & 241.55 & 263.11 & 26.26 & 25.41 \\
\hline B04 & 18.7 & 24.78 & 22.95 & 10.38 & 9.12 & 229.91 & 261.78 & 9.64 & 9.03 \\
\hline B04 & 21.0 & 31.14 & 30.06 & 14.61 & 13.61 & 232.52 & 260.89 & 14.30 & 13.29 \\
\hline B04 & 36.5 & 64.69 & 63.53 & 23.54 & 21.80 & 229.18 & 255.05 & 23.21 & 21.67 \\
\hline B05 & 18.7 & 35.56 & 33.28 & 7.71 & 8.02 & 233.71 & 255.74 & 8.01 & 8.29 \\
\hline B05 & 21.0 & 43.27 & 41.96 & 13.73 & 12.75 & 242.98 & 257.92 & 15.28 & 13.40 \\
\hline B05 & 36.5 & 85.16 & 88.68 & 22.57 & 21.87 & 226.33 & 241.98 & 22.84 & 21.94 \\
\hline B05 & 89.0 & 162.60 & 161.70 & 42.60 & 33.90 & 178.50 & 175.20 & 43.50 & 36.00 \\
\hline B05 & 150.0 & 199.70 & 187.60 & 67.40 & 54.00 & 195.70 & 186.10 & 67.70 & 57.40 \\
\hline B06 & 18.7 & 22.89 & 22.31 & 9.02 & 8.43 & 238.45 & 260.81 & 9.11 & 8.27 \\
\hline B06 & 21.0 & 30.09 & 28.78 & 12.46 & 12.46 & 239.06 & 261.53 & 12.49 & 11.37 \\
\hline B06 & 36.5 & 63.62 & 62.54 & 21.83 & 21.34 & 236.89 & 258.01 & 21.95 & 21.39 \\
\hline B06 & 89.0 & 195.4 & 200.85 & 30.05 & 30.05 & 208.27 & 210.84 & 38.43 & 31.09 \\
\hline B06 & 150.0 & 201.43 & 194.45 & 44.46 & 44.46 & 202.49 & 193.59 & 60.18 & 43.68 \\
\hline B07 & 18.7 & 55.39 & 55.25 & 10.18 & 9.65 & 209.77 & 242.70 & 10.08 & 9.50 \\
\hline B07 & 21.0 & 62.84 & 64.10 & 12.72 & 12.22 & 214.42 & 243.58 & 12.23 & 11.74 \\
\hline B07 & 36.5 & 124.04 & 131.10 & 21.12 & 20.80 & 195.59 & 211.41 & 21.83 & 20.91 \\
\hline B07 & 89.0 & 167.92 & 165.34 & 37.24 & 29.18 & 167.85 & 165.21 & 35.02 & 27.93 \\
\hline B07 & 150.0 & 190.38 & 180.01 & 57.67 & 45.89 & 189.56 & 179.56 & 51.66 & 44.31 \\
\hline
\end{tabular}

transfer approach to model the microwave brightness temperature. It is capable of treating the snow as a single homogeneous layer (Pulliainen et al., 1999) or as a series of homogeneous layers (Lemmetyinen et al., 2010), with the layers being defined by its physical temperature, density, observed grain diameter, and SWE.

The model's basic assumption is that the microwave radiation is scattered mostly in the forward direction, which allows simplifying the radiative transfer equation to a single flux. Calculation of the absorption coefficient in the HUT model is based on empirical models by Mätzler (1987); while the total extinction coefficient (sum of absorption and scattering coefficients) was originally calculated by Hallikainen et al. (1987) from observations of natural snow slabs collected in southern Finland. The extinction coefficients calculated by Hallikainen et al. (1987) is valid between 18 and $90 \mathrm{GHz}$. Calculation of the total extinction coefficient was originally based on the mean observed grain size (Table 1, Hallikainen et al., 1987), which can be interpreted to be close to the traditional measure of grain size, $E$ (Fierz et al., 2009). However, an effective grain size $D_{\text {eff }}$, i.e. the grain size value that cor- responds to the total scattering effects from the snowpack, was later introduced by Kontu and Pulliainen (2010) to alleviate large errors arising from the use of $E$ in model simulations. According to Kontu and Pulliainen (2010), effective grain size and traditional grain size are related by

$D_{\text {eff }}=\left(1-e^{-1.5 E}\right)$.

Other extinction coefficient relationships exist for the HUT model (Roy et al., 2004; Kontu and Pulliainen, 2010), but these have not been used here. A possible reason for discrepancies noted by both Kontu and Pulliainen (2010) as well as Roy et al. (2004) for coarse grained snow is that measured $E$ in the data set by Hallikainen et al. (1987) extended only up to $1.6 \mathrm{~mm}$. The extinction coefficient model may thus not hold for $E>1.6 \mathrm{~mm}$.

The HUT model uses up- and downwelling emissions, represented by single-flux approximations, to calculate the total emission at the top of the snowpack. Multiple reflections at layer interfaces are accounted. Separate modules were used to simulate the effect of vegetation and atmosphere to de- 
tected emission were published with the original model, but were not applied here.

\subsubsection{Microwave Emission Model of Layered Snowpacks}

MEMLS (Wiesmann and Mätzler, 1999; Mätzler and Wiesmann, 1999) is also based on radiative transfer theory, treating the snowpack as a stack of horizontal layers, with each layer being characterized by its depth, physical temperature, density, and exponential correlation length. Although exponential correlation length $P_{e x}$ was not directly measured, it can be calculated via measurements of density (Mätzler, 2002) and SSA (Toure et al., 2008), such that:

$P_{\text {ex }}=\frac{3\left(1-\frac{\rho_{\text {snow }}}{\rho_{\text {ice }}}\right)}{\text { SSA }}$

where $\rho_{\text {snow }}$ is the density of snow, and $\rho_{\text {ice }}$ is the density of ice $\left(917 \mathrm{~kg} \mathrm{~m}^{-3}\right)$.

These data are used to calculate absorption and scattering coefficients within the snow, as well as transmissivity and reflectivity between adjacent snow layers. A two-flux (up- and downwelling) model is used to calculate the emitted brightness temperature at the top of the snowpack. However, the absorption and scattering coefficients are adjusted with six flux coefficients (up- and downwelling, and four horizontal directions). The scattering coefficient was empirically defined from radiometric and macro- and microstructure measurements as laid out by Wiesmann et al. (1998) and it is valid between 10 and $100 \mathrm{GHz}$. An optional feature, originally implemented for coarse-grained snow with a large correlation length, is to use the improved Born approximation (Mätzler and Wiesmann, 1999) for the calculation of the scattering coefficient.

\section{Results}

\subsection{Macro- and microstructure observations}

Preliminary analyses of snow macro- and microstructure measurements include slab thickness, physical temperature, density, SSA, grain size $E$, and homogeneity. $E$ ranged from 0.5 to $2.0 \mathrm{~mm}$, average slab densities ranged from 130 to $340 \mathrm{~kg} \mathrm{~m}^{-3}$, and physical snow temperature ranged from -14 to $0{ }^{\circ} \mathrm{C}$. The variability of snow characteristics and homogeneity from all 14 slabs are shown in Table 3. Bulk averages and standard deviations of micro-CT-derived SSA and density values are given in Table 4. Locally calibrated bulk averages and standard deviations of SMP-derived SSA and density values are given in Table 5.

\subsection{Comparison of snow emission models}

The parameters from the eight dry homogeneous slabs in Table 3 were fed into both the single-layer HUT snow emis-

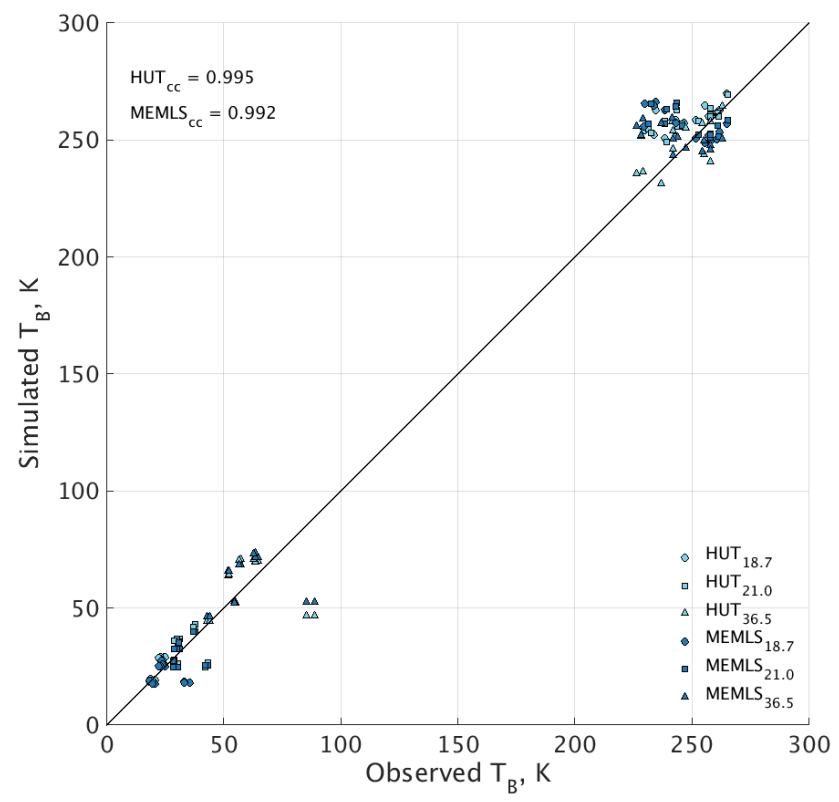

Figure 4. HUT (light blue) and MEMLS (dark blue) simulated brightness temperatures plotted against observed brightness temperatures at 18.7 (circle), 21.0 (square), and $36.5 \mathrm{GHz}$ (triangle). The correlation coefficients of the single-layer HUT model $\left(\mathrm{HUT}_{\mathrm{CC}}\right)$ and MEMLS $\left(\right.$ MEMLS $_{\mathrm{CC}}$ ) are also displayed.

sion model and into MEMLS to produce simulated brightness temperatures. The ground layer in both of the models was modified to simulate the absorbing and reflecting bases by altering the reflecting properties of the ground, to model the reflective properties of the metal plate $(r=1)$ and the absorbing base $(r=0)$. The absorbing and reflective bases were simulated assuming a near-perfect absorption and reflection at the snow-base interface. The directly measured downwelling sky contribution was applied as the downwelling flux in both models. The simulated brightness temperatures at $18.7,21.0$, and $36.5 \mathrm{GHz}$ were compared to the observed brightness temperatures, as shown in Fig. 4, and the 2-D correlation coefficient for each model was calculated. The RMSE and bias values were calculated for each base simulation, at both horizontal and vertical polarizations. The RMSE and bias at the two higher frequencies $(89.0$ and $150.0 \mathrm{GHz})$ were not calculated for this study. Figure 5 shows the RMSE values and Fig. 6 shows the bias values of the simulations.

The values in Fig. 5 show that for the absorbing base, the HUT model simulations tend to have smaller RMSE values than MEMLS, while for the reflective base simulations the RMSE values are comparable at 18.7 and $21.0 \mathrm{GHz}$. At $36.5 \mathrm{GHz}$ the HUT snow emission model produces larger RMSE values than MEMLS. The RMSE values for the absorbing base of vertical polarization (V-ABS) are the smallest.

It can be seen from Fig. 6 that the reflective base cases have the smallest bias, with 18.7 and $21.0 \mathrm{GHz}$ only having very 
Table 3. Averaged results from macro- and microstructure measurements. It should be noted that slab A03 was wet, so was not considered for model simulation.

\begin{tabular}{|c|c|c|c|c|c|c|c|c|c|c|c|c|}
\hline \multirow[t]{2}{*}{ Date } & \multirow[t]{2}{*}{$\begin{array}{l}\text { Slab } \\
\text { ref. }\end{array}$} & \multicolumn{2}{|c|}{$\begin{array}{c}\text { Temperature } \\
\left({ }^{\circ} \mathrm{C}\right)\end{array}$} & \multicolumn{2}{|c|}{$\begin{array}{c}\text { Density } \\
\left(\mathrm{kg} \mathrm{m}^{-3}\right)\end{array}$} & \multicolumn{2}{|c|}{$\begin{array}{l}\text { Grain size } \\
(\mathrm{mm})\end{array}$} & \multicolumn{2}{|c|}{$\begin{array}{c}\text { SSA } \\
\left(\mathrm{m}^{2} \mathrm{~kg}^{-1}\right)\end{array}$} & \multicolumn{2}{|c|}{$\begin{array}{c}\text { Thickness } \\
(\mathrm{cm})\end{array}$} & \multirow[t]{2}{*}{ Homogenous } \\
\hline & & $\begin{array}{r}\text { Bulk } \\
\text { avg. }\end{array}$ & SD & $\begin{array}{l}\text { Bulk } \\
\text { avg. }\end{array}$ & $\mathrm{AD}$ & $\begin{array}{l}\text { Bulk } \\
\text { avg. }\end{array}$ & SD & $\begin{array}{l}\text { Bulk } \\
\text { avg. }\end{array}$ & SD & $\begin{array}{l}\text { Bulk } \\
\text { avg. }\end{array}$ & SD & \\
\hline 13 Jan 2014 & A01 & -13.1 & 0.1 & 135.5 & 28.4 & 0.5 & 0.1 & 35.8 & 6.3 & 17.8 & 0.8 & Yes \\
\hline 14 Jan 2014 & A02 & -22.2 & 0.4 & 264.2 & 21.6 & 0.7 & 0.2 & 15.4 & 5.6 & 15.6 & 0.4 & No \\
\hline $11 \mathrm{Feb} 2014$ & A03 & -0.3 & 0.4 & 227.7 & 41.9 & 0.6 & 0.2 & 18.0 & 4.5 & 16.6 & 0.5 & Yes \\
\hline $13 \mathrm{Feb} 2014$ & A04 & -0.5 & 0.4 & 225.7 & 41.9 & 0.9 & 0.3 & 11.3 & 2.3 & 18.0 & 0.5 & No \\
\hline 3 Mar 2014 & A05 & -0.8 & 0.1 & 286.7 & 36.5 & 0.9 & 0.2 & 15.8 & 3.7 & 15.6 & 0.4 & No \\
\hline 18 Mar 2014 & A06 & -7.6 & 0.7 & 280.0 & 14.9 & 0.8 & 0.2 & 17.5 & 2.7 & 14.8 & 0.7 & Yes \\
\hline 20 Mar 2014 & A07 & -5.1 & 3.5 & 284.8 & 15.2 & 0.9 & 0.1 & 15.5 & 2.6 & 14.8 & 0.3 & No \\
\hline 2 Feb 2015 & B01 & -13.2 & 0.9 & 139.5 & 23.9 & 0.5 & 0.1 & 36.4 & 5.9 & 14.8 & 0.3 & Yes \\
\hline 5 Feb 2015 & В02 & -10.9 & 0.2 & 160.3 & 34.1 & 0.5 & 0.1 & 36.4 & 8.0 & 13.9 & 0.2 & Yes \\
\hline 19 Feb 2015 & B03 & -2.6 & 0.4 & 234.0 & 24.0 & 0.6 & 0.1 & 22.8 & 4.0 & 14.9 & 0.2 & Yes \\
\hline 11 Mar 2015 & B04 & -5.4 & 0.2 & 268.2 & 26.3 & 1.1 & 0.1 & 21.2 & 2.0 & 16.2 & 0.3 & Yes \\
\hline 12 Mar 2015 & B05 & -3.2 & 0.5 & 337.5 & 9.0 & 1.9 & 0.1 & 10.3 & 0.3 & 5.4 & 0.4 & Yes \\
\hline 24 Mar 2015 & B06 & -5.4 & 0.3 & 315.0 & 17.5 & 1.3 & 0.1 & 17.3 & 2.4 & 14.5 & 0.4 & Yes \\
\hline 25 Mar 2015 & В07 & -3.7 & 0.4 & 282.5 & 17.1 & 2.0 & 0.2 & 9.4 & 0.5 & 15.2 & 0.3 & No \\
\hline
\end{tabular}
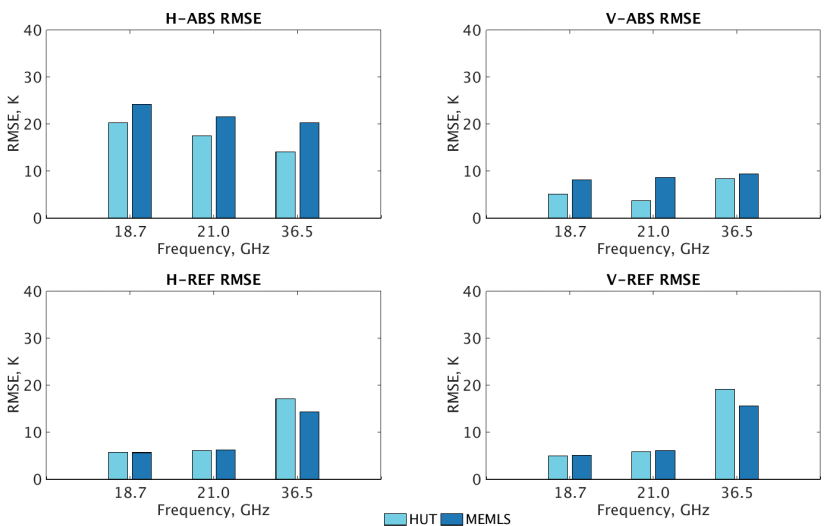

Figure 5. Simulated brightness temperature RMSE at horizontal $(\mathrm{H})$ and vertical $(\mathrm{V})$ polarizations for the absorber material base (ABS) and the reflective metal plate base (REF). Eight slabs were simulated at 18.7 and $21.0 \mathrm{GHz}$, while seven slabs were simulated at $36.5 \mathrm{GHz}$.

small magnitude $(<|2 \mathrm{~K}|)$ biases. At $36.5 \mathrm{GHz}$, the HUT model is negatively biased and MEMLS is slightly positively biased. It suggests that the HUT model underestimated the microwave emission while MEMLS slightly overestimated it at $36.5 \mathrm{GHz}$ on the reflective base cases. The bias for the absorbing base of horizontal polarization ( $\mathrm{H}-\mathrm{ABS}$ ) was positive regardless of model or frequency. The bias for the VABS simulations $(<|6 \mathrm{~K}|)$ was negative for all frequencies with MEMLS, and with HUT model positive at 18.7 and $21.0 \mathrm{GHz}$, and slightly negative at $36.5 \mathrm{GHz}$.

The larger magnitude bias in the REF situations in the single-layer HUT simulations can be attributed to the way
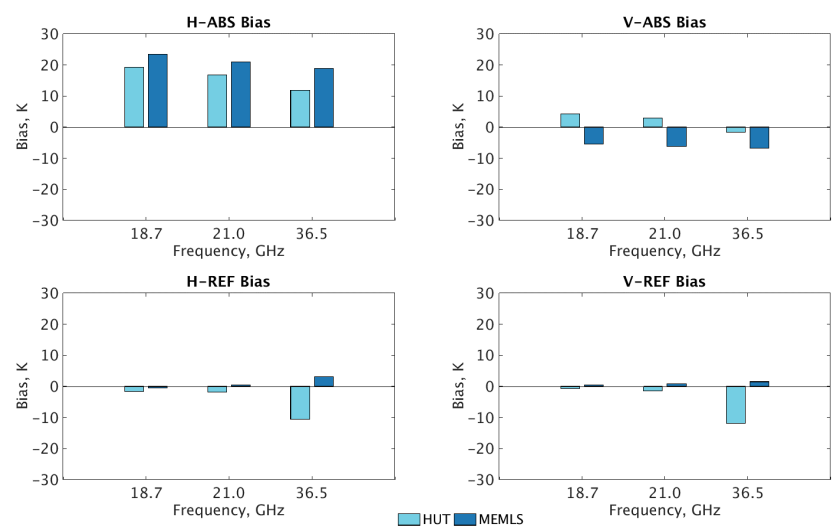

Figure 6. Simulated brightness temperature bias at horizontal $(\mathrm{H})$ and vertical $(V)$ polarizations for the absorber material base (ABS) and the reflective metal plate base (REF). Eight slabs were simulated at 18.7 and $21.0 \mathrm{GHz}$, while seven slabs were simulated at $36.5 \mathrm{GHz}$.

which the simulated emission is calculated. The bias in HUT for both REF situations is largely reduced (bias $<|3 \mathrm{~K}|$ ), when the snow thickness is doubled. This doubling of snow depth mimics the doubling of the path length that the downwelling radiation must travel through when the ground is a near perfect reflector (as the downwelling radiation passes through the slab to the reflective plate, is reflected, then travels back through the snow slab). By not doubling the snow depth, the single-layer HUT snow emission model does not correctly model the experimental situation, as it only models the radiation propagating from the ground to the surface, thus underestimating the reflective simulations. 
Table 4. Micro-CT-derived bulk average and standard deviation values of SSA and density. The values for A and B correspond to positions A and B in Fig. 3. Micro-CT A02A was not analysed, thus values of SSA and density are not given.

\begin{tabular}{|c|c|c|c|c|c|c|c|c|}
\hline \multirow{3}{*}{$\begin{array}{l}\text { Position } \\
\text { Slab } \\
\text { ref. }\end{array}$} & \multicolumn{4}{|c|}{$\mathrm{SSA}\left(\mathrm{m}^{2} \mathrm{~kg}^{-1}\right)$} & \multicolumn{4}{|c|}{ Density $\left(\mathrm{kg} \mathrm{m}^{-3}\right)$} \\
\hline & \multicolumn{2}{|c|}{ A } & \multicolumn{2}{|c|}{ B } & \multicolumn{2}{|c|}{ A } & \multicolumn{2}{|c|}{ B } \\
\hline & $\begin{array}{c}\text { Bulk } \\
\text { avg. }\end{array}$ & $\mathrm{SD}$ & $\begin{array}{c}\text { Bulk } \\
\text { avg. }\end{array}$ & $\mathrm{SD}$ & $\begin{array}{r}\text { Bulk } \\
\text { avg. }\end{array}$ & SD & $\begin{array}{c}\text { Bulk } \\
\text { avg. }\end{array}$ & SD \\
\hline A01 & 29.3 & 4.3 & 29.9 & 4.3 & 95.6 & 40.7 & 91.3 & 35.9 \\
\hline A02 & $X$ & $X$ & 13.1 & 4.3 & $X$ & $X$ & 250.0 & 65.7 \\
\hline A03 & 16.2 & 5.2 & 16.6 & 5.5 & 202.4 & 48.5 & 198.6 & 45.6 \\
\hline A04 & 9.3 & 2.0 & 9.4 & 2.2 & 311.9 & 62.1 & 308.2 & 64.5 \\
\hline A05 & 9.9 & 3.7 & 9.8 & 2.4 & 285.0 & 62.7 & 283.4 & 47.6 \\
\hline A06 & 12.7 & 2.2 & 12.9 & 2.2 & 277.0 & 28.6 & 270.7 & 29.7 \\
\hline A07 & 10.6 & 2.2 & 10.9 & 1.2 & 288.6 & 86.8 & 270.1 & 25.4 \\
\hline B01 & 27.0 & 4.0 & 28.0 & 3.9 & 136.7 & 54.4 & 147.0 & 52.7 \\
\hline B02 & 24.7 & 3.6 & 26.0 & 3.7 & 189.3 & 62.5 & 176.5 & 60.2 \\
\hline B03 & 16.6 & 1.4 & 16.6 & 1.3 & 249.8 & 34.0 & 253.7 & 35.1 \\
\hline B04 & 16.2 & 2.4 & 15.8 & 2.3 & 267.8 & 40.4 & 272.2 & 39.7 \\
\hline B05 & 8.2 & 1.1 & 8.5 & 0.3 & 321.1 & 69.3 & 318.5 & 43.8 \\
\hline B06 & 12.7 & 1.0 & 12.8 & 1.0 & 319.1 & 32.5 & 318.7 & 24.0 \\
\hline B07 & 7.8 & 0.7 & 8.1 & 0.7 & 325.7 & 42.2 & 289.2 & 36.3 \\
\hline
\end{tabular}

Table 5. Locally calibrated SMP-derived bulk average and standard deviation values of SSA and density. The values for B2 and C2 correspond to positions B2 and C2 in Fig. 3.

\begin{tabular}{|c|c|c|c|c|c|c|c|c|}
\hline \multirow{3}{*}{$\begin{array}{l}\text { Position } \\
\text { Slab } \\
\text { ref. }\end{array}$} & \multicolumn{4}{|c|}{$\mathrm{SSA}\left(\mathrm{m}^{2} \mathrm{~kg}^{-1}\right)$} & \multicolumn{4}{|c|}{ Density $\left(\mathrm{kg} \mathrm{m}^{-3}\right)$} \\
\hline & \multicolumn{2}{|c|}{ B2 } & \multicolumn{2}{|c|}{$\mathrm{C} 2$} & \multicolumn{2}{|c|}{ B2 } & \multicolumn{2}{|c|}{$\mathrm{C} 2$} \\
\hline & $\begin{array}{c}\text { Bulk } \\
\text { avg. }\end{array}$ & $\mathrm{SD}$ & $\begin{array}{c}\text { Bulk } \\
\text { avg. }\end{array}$ & $\mathrm{SD}$ & $\begin{array}{c}\text { Bulk } \\
\text { avg. }\end{array}$ & SD & $\begin{array}{c}\text { Bulk } \\
\text { avg. }\end{array}$ & SD \\
\hline A01 & 38.0 & 4.8 & 39.0 & 5.6 & 147.2 & 35.4 & 144.1 & 37.9 \\
\hline $\mathrm{A} 02$ & 21.7 & 3.7 & 21.6 & 3.0 & 295.6 & 38.7 & 297.3 & 37.6 \\
\hline A03 & 28.2 & 4.3 & 28.5 & 3.9 & 201.2 & 30.1 & 198.6 & 26.5 \\
\hline A04 & 19.2 & 4.6 & 18.2 & 7.9 & 268.9 & 39.1 & 275.6 & 44.8 \\
\hline A05 & 21.9 & 4.6 & 21.7 & 5.4 & 255.3 & 36.8 & 246.6 & 32.9 \\
\hline A06 & 24.2 & 2.4 & 23.9 & 3.4 & 261.6 & 24.5 & 269.2 & 34.6 \\
\hline A07 & 24.6 & 2.2 & 24.7 & 1.4 & 254.3 & 20.9 & 253.9 & 14.7 \\
\hline B01 & 26.1 & 3.3 & 26.2 & 3.3 & 230.5 & 25.1 & 228.5 & 25.8 \\
\hline B02 & 27.8 & 2.3 & 27.9 & 2.9 & 216.7 & 23.1 & 217.7 & 26.8 \\
\hline B03 & 27.5 & 2.5 & 26.5 & 1.4 & 220.2 & 15.1 & 227.4 & 12.3 \\
\hline B04 & 26.3 & 5.2 & 26.7 & 5.9 & 230.1 & 45.9 & 225.8 & 47.6 \\
\hline B05 & 18.5 & 4.2 & 18.6 & 4.5 & 254.0 & 15.1 & 263.3 & 30.0 \\
\hline B06 & 20.8 & 1.5 & 21.1 & 1.9 & 289.7 & 16.2 & 285.3 & 21.2 \\
\hline В07 & 23.2 & 5.9 & 21.8 & 4.5 & 256.7 & 54.3 & 267.0 & 38.9 \\
\hline
\end{tabular}

The doubling of the snow thickness also reduces the errors introduced by slab B05 (initial thickness $5.4 \mathrm{~cm}$ ), as the small thickness is not enough for scattering to be correctly simulated. Additional errors will be introduced, due to the slight changes in the snow density and microstructural parameter that were not recorded by the traditional observations, due to the coarse resolution of the method (vertical profile of 3$5 \mathrm{~cm})$. There were variations in density and SSA that were recorded by the micro-CT and SMP observations, but were not recorded with the traditional observation techniques.

\section{Summary}

The Arctic Snow Microstructure Experiment (ASMEx) consisted of radiometric, macro-, and microstructure measurements of snow slabs upon absorbing and reflecting bases. 
Brightness temperatures of the homogeneous snow slabs were simulated with the HUT snow emission model and with MEMLS. Results of the comparison of simulations and observations are described in Sect. 3.2. The HUT model produced smaller RMSE across all three frequencies for the simulations upon an absorbing base. The reflective base simulations produced RMSE values that were comparable with the HUT model and MEMLS at 18.7 and $21.0 \mathrm{GHz}$. Both models overestimated the brightness temperature at $\mathrm{H}-\mathrm{ABS}$, and at V-ABS the single-layer HUT model slightly overestimated the brightness temperature while MEMLS underestimated it. Both models produced very small biases for the reflective base cases, with the exception of the HUT model at $36.5 \mathrm{GHz}$.

The RMSE and bias is influenced by internal extinction processes within the snow slabs, which are imperfectly simulated by the model physics. The relatively high errors, especially at $\mathrm{H}$ pol, considering the highly controlled measurement setup, highlight the requirement for further development of the models, as well as the need to better quantify the snow microstructural properties themselves. These preliminary brightness temperature simulations will be repeated in the future using the physical snow properties collected by the modern techniques including SMP and micro-CT measurements. Ultimately, a revised extinction model will be created for the HUT snow emission model, and implemented with the aim to improve the model inversions of SWE from radiometric measurements of microwave emission. This revised extinction coefficient, based on the data collected during the ASMEx campaign, will be a function of microstructural parameter and frequency.

Author contributions. Juha Lemmetyinen, Mel Sandells, and Martin Schneebeli planned the experiment with help of William Maslanka. William Maslanka had the main responsibility in organizing and carrying out the measurements. Leena Leppänen had the responsibility of organizing measurements as the local operator, including implementation of measurement setup and participation to measurement procedure. Anna Kontu and HennaReetta Hannula participated in the experimental measurements. William Maslanka conducted data processing and simulations. Margret Matzl provided the micro-CT data set. Martin Proksch provided the SMP analysis. William Maslanka and Leena Leppänen prepared the manuscript with contributions from all co-authors.

Acknowledgements. We thank the staff of FMI Arctic Research Centre in Sodankylä for performing the ground-based radiometer measurements and macro- and microstructure measurements. We also thank the staff of WSL Institute of Snow and Avalanche Research SLF for the SMP instrument and for the SMP and microCT analyses of the snow samples. The manuscript preparation was supported by the EU 7th Framework Program project "EuropeanRussian Centre for cooperation in the Arctic and Sub-Arctic environmental and climate research" (EuRuCAS, Grant no. 295068).
Edited by: C. Ménard

\section{References}

Amlien, J.: Remote Sensing of Snow with Passive Microwave Radiometers - A review of current algorithms, Report 1019, Norsk Regnesentral, Oslo, 1-52, 2008.

Armstrong, A., Chang, A., Rango, A., and Josberger, E.: Snow depths and grain-size relationships with relevance for passive microwave studies, Ann. Glaciol., 17, 171-176, 1993.

Barnett, T. P., Adam, J. C., and Lettenmaier, D. P.: Potential Impacts of a Warming Climate on Water Availability in Snow-Dominated Regions, Nature, 438, 303-309, 2005.

Chang, A. T. C., Foster, J. L., and Hall, D. K.: Nimbus-7 SMMR derived global snow parameters, Ann. Glaciol., 9, 39-44, 1987.

Cohen, J. and Rind, D.: The effect of snow cover on the climate, J. Climate, 4, 689-706, 1991.

Derksen, C., Walker, A., and Goodison, B.: A comparison of 18 winter seasons of in situ and passive microwave derived snow water equivalent estimates in Western Canada, Remote Sens. Environ., 88, 271-282, 2003.

Fierz, C., Armstrong, R. L., Durand, Y., Etchevers, P., Greene, E., McClung, D. M., Nishimura, K., Satyawali, P. K., and Sokratov, S. A.: The International Classification for Seasonal Snow on the Ground, IHP-VII Technical Documents in Hydrology No. 83, IACS Contribution No. 1, UNESCO-IHP, Paris, 1-90, 2009.

Foster, J., Hall, D., Chang, A., Rango, A., Wergin, W., and Erbe, E.: Effects on snow crystal shape on the scattering of passive microwave radiation, IEEE T. Geosci. Remote, 37, 1165-1168, 1999.

Gallet, J.-C., Domine, F., Zender, C. S., and Picard, G.: Measurement of the specific surface area of snow using infrared reflectance in an integrating sphere at 1310 and $1550 \mathrm{~nm}$, The Cryosphere, 3, 167-182, doi:10.5194/tc-3-167-2009, 2009.

Hallikainen, M.: Microwave Radiometry of Snow, Adv. Space Res., 9, 267-275, 1989.

Hallikainen, M., Ulaby, F., and Van Deventer, T.: Extinction Behaviour of Dry Snow in the $18-$ to $90-\mathrm{GHz}$ Range, IEEE T. Geosci. Remote, 25, 737-745, 1987.

Heggli, M., Frei, M., and Schneebeli, M.: Snow replica method for three-dimensional X-ray microtomography imaging, J. Glaciol., 55, 631-639, 2009.

Hollinger, J., Peirce, J., and Poe, G.: SSM/I Instrument Evaluation, IEEE T. Geosci. Remote, 28, 781-790, 1990.

Kelly, R., Chang, A., Tsang, L., and Foster, J.: A Prototype AMSRE Global Snow Area and Snow Depth Algorithm, IEEE T. Geosci. Remote, 41, 230-242, 2003.

Kontu, A. and Pulliainen, J.: Simulation of spaceborne microwave radiometer measurements of snow cover using in situ data and brightness temperature modelling, IEEE T. Geosci. Remote, 48, 1031-1044, 2010.

Künzi, F., Patil, S., and Rott, H.: Snow-cover parameters retrieved from Nimbus-7 Scanning Multi-channel Microwave Radiometer (SMMR) data, IEEE T. Geosci. Remote, 20, 452-467, 1982.

Legagneux, L., Cabanes, A., and Dominé, F.: Measurement of the specific surface area of 176 snow samples using methane adsorption at $77 \mathrm{~K}$, J. Geophys. Res.-Atmos., 107, 4335, doi:10.1029/2001JD001016, 2002. 
Lemmetyinen, J., Pulliainen, J., Rees, A., Kontu, A., Qiu, Y., and Derksen, C.: Multiple-layer adaptation of HUT snow emission model: comparison with experimental data, IEEE T. Geosci. Remote, 48, 2781-2794, 2010.

Mätzler, C.: Applications of the interaction of microwave with the natural snow cover, Remote Sens. Rev., 2, 259-387, 1987.

Mätzler, C.: Relation between grain-size and correlation length of snow, J. Glaciol., 48, 461-466, 2002.

Mätzler, C. and Wiesmann, A.: Extension of the Microwave Emission Model of Layered Snowpacks to Coarse-Grained Snow, Remote Sens. Environ., 70, 317-325, 1999.

Pan, J., Durand, M., Sandells, M., Lemmetyinen, J., Kim, E., Pulliainen, J., Kontu, A., and Derksen, C.: Differences between the HUT Snow Emission Model and MEMLS and Their Effects on Brightness Temperature Simulation, IEEE T. Geosci. Remote, 99, 1-19, 2015.

Proksch, M., Löwe, H., and Schneebeli, M.: Density, specific surface area, and correlation length of snow measured by highresolution penetrometry, J. Geophys. Res.-Earth, 120, 346-362, 2015.

Pulliainen, J., Grandell, J., and Hallikainen, M.: HUT snow emission model and its applicability to snow water equivalent retrieval, IEEE T. Geosci. Remote, 37, 1378-1390, 1999.

Roy, V., Goita, K., Royer, A., Walker, A., and Goodson, B.: Snow Water Equivalent Retrieval in a Canadian Boreal Environment from Microwave Measurements using the HUT Snow Emission Model, IEEE T. Geosci. Remote, 42, 1850-1859, 2004.
Schneebeli, M. and Johnson, J. B.: A constant-speed penetrometer for high-resolution snow stratigraphy, Ann. Glaciol., 26, 107$111,1998$.

Schneebeli, M., Pielmeier, C., and Johnson, J. B.: Measuring snow microstructure and hardness using a high resolution penetrometer, Cold Reg. Sci. Technol., 30, 101-114, 1999.

Stiles, W. and Ulaby, F.: Dielectric properties of snow, Technical Report 527-1, The University of Kansas Center for Research, Inc. Remote Sensing Laboratory, Lawrence, Kansas, 93-103, 1981.

Takala, M., Luojus, K., and Pulliainen, J.: Estimating Northern Hemisphere Snow Water Equivalent for Climate Research through Assimilation of Space-Borne Radiometer Data and Ground-Based Measurements, Remote Sens. Environ., 15, $3517-$ 3529, 2011.

Toure, A., Goite, K., Royer, A., Mätzler, C., and Schneebeli, M.: Near-infrared digital photography to estimate snow correlation length for microwave emission modelling, Appl. Optics, 48, 111, 2008.

Tsang, L., Chen, C.-T., Chang, A., Guo, J., and Ding, K.-H.: Dense media radiative transfer theory based on quasicrystalline approximation with application to passive microwave remote sensing of snow, Radio Sci., 35, 731-749, 2000.

Wiesmann, A. and Mätzler, C.: Microwave Emission Model of Layered Snowpacks, Remote Sens. Environ., 70, 307-316, 1999.

Wiesmann, A., Mätzler, C., and Weise, T.: Radiometric and structural measurements of snow samples, Radio Science, 33, 273 $289,1998$. 